\title{
The ageing of lung function: cross-sectional and longitudinal studies of an Inuit community
}

\author{
A. Rode, R.J. Shephard
}

The ageing of lung function: cross-sectional and longitudinal studies of an Inuit community. A. Rode, R. J. Shephard. CERS Journals Ltd 1994.

ABSTRACT: Three surveys (1969/1970, 1979/1980 and 1989/1990) have examined the impact of acculturation to a sedentary lifestyle on the pulmonary function of a circumpolar native Inuit community.

The sample comprised more than 50\% of those aged 20-60 yrs, most recently 119 males and 92 females. Forced vital capacity (FVC), forced expiratory volume in one second $\left(F E V_{1}\right)$ and maximal mid-expiratory flow (MMEF) were measured by standard spirometric techniques, and information was obtained on smoking habits and health.

Multiple regression equations showed that lung function was affected by height and age, but usually not by age squared. Cross-sectional age coefficients for FVC and FEV $V_{1}$ increased over the period 1969/1970 to 1989/1990. Parallel longitudinal trends were seen in $\mathrm{FEV}_{1}$ (males only). Multiple analysis of variance (MANOVA) showed age-decade* cohort effects for $\mathrm{FVC}$ and $\mathrm{FEV}_{1}$ (males but not females). Almost all of the population now smoke (mean \pm sD males $13 \pm 8$ cigarettes day $^{-1}$; females $11 \pm 7$ cigarettes $\cdot$ day $\left.^{-1}\right)$. However, smoking bears little relationship to lung function perhaps due to limited variance in consumption. About a third of the community have physician-diagnosed and/or radiographically visible chest disease, but with little effect upon pulmonary function.

We conclude that an apparent secular trend to a faster ageing of lung function in men is not explained by disease or domestic air pollution. Possible factors include increased lung volumes in young adults, greater pack-years of cigarette exposure, nonspecific respiratory disease, increased inspiration of cold air or altered chest mechanics due to operation of high-speed snowmobiles, and loss of physical fitness. Eur Respir J., 1994, 7, 1653-1659.
School of Physical \& Health Education and Dept of Preventive Medicine \& Biostatistics, Faculty of Medicine, University of Toronto, Canada.

Correspondence: R.J. Shephard

School of Physical \& Health Education 320, Huron St

Toronto

ON M5S, 1A1

Canada

Keywords: Acculturation

cold exposure

lung function

physical fitness

radiographic chest disease

smoking

Recieved: April 91993

Accepted after revision April 131994

This research was supported in part by research grants from Health and Welfare, Canada, and Canadian Tire Acceptance Limited.
The apparent rate of ageing of lung function differs between cross-sectional and longitudinal surveys [1-4]. Longitudinal data may be biased by recruitment of a health-conscious sample, selective retention or loss of subjects with respiratory disease, intersurvey changes in spirometer characteristics, learning of techniques, and secular changes of habitual physical activity (particularly among indigenous populations where there has been rapid adoption of a sedentary lifestyle). Crosssectional studies may be biased by cohort effects (differential exposure to disease, cigarettes and air pollutants) and secular trends in adult stature [3], or the age distribution of a population.

Many variables influencing both cross-sectional and longitudinal data have operated in the Canadian Arctic over the past $20 \mathrm{yrs}$. Our data were collected on residents of Igloolik $\left(69^{\circ} 40^{\prime} \mathrm{N}, 81^{\circ} \mathrm{W}\right)$. In $1969 /$ 1970 [5], many of the population continued traditional hunting and fishing activities [6], and physical fitness levels were high [7]. During the subsequent $20 \mathrm{yrs}$, there was rapid acculturation to a sedentary lifestyle [8], with associated changes in the prevalence of respiratory disease, exposure to arctic air and air pollutants (including cigarette smoke), cigarette consumption, adult stature [9], and survival to old age.

By 1979/1980, there was a substantial deterioration of physical condition [10], with some increase in crosssectional coefficients describing the ageing of lung function [11]. Outdoor activity has subsequently decreased further, with the arrival of satellite television and video-rental outlets [8]. It was, thus, thought of interest to document changes of respiratory health from 1969/ 1970 until 1989/1990, as seen in both cross-sectional and longitudinal data.

Methods

\section{Subjects and experimental plan}

Measurements of lung function were made in 1969/1970, $1979 / 1980$, and 1989/1990. More of the population were surviving to old age by $1989 / 1990$; to avoid biasing our data, we restricted analyses to subjects aged 20-60 yrs. 
Table 1. - Sample size for the three cross-sectional (C) and two longitudinal (L) comparisons

\begin{tabular}{|c|c|c|c|c|c|c|c|c|c|c|}
\hline \multirow[b]{3}{*}{$\begin{array}{l}\text { Age } \\
\text { yrs }\end{array}$} & \multicolumn{5}{|c|}{ Males } & \multicolumn{5}{|c|}{ Females } \\
\hline & 1970 & 1980 & 1990 & $1970-80$ & 1980-90 & 1970 & 1980 & 1990 & 1970-80 & 1980-90 \\
\hline & $\mathrm{C}$ & $\mathrm{C}$ & $\mathrm{C}$ & $\mathrm{L}$ & $\mathrm{L}$ & $\mathrm{C}$ & $\mathrm{C}$ & C & $\mathrm{L}$ & $\mathrm{L}$ \\
\hline $20-29$ & 34 & 38 & 70 & 19 & 19 & 21 & 24 & 46 & 7 & 10 \\
\hline $30-39$ & 24 & 31 & 24 & 15 & 16 & 12 & 23 & 16 & 5 & 13 \\
\hline $40-49$ & 8 & 18 & 16 & 5 & 10 & 4 & 17 & 19 & 5 & 9 \\
\hline $50-59$ & 7 & 10 & 10 & & & 6 & 6 & 12 & & \\
\hline
\end{tabular}

Volunteers were tested using a protocol approved by the Igloolik Hamlet Council and the University of Toronto Committee on Human Experimentation. Procedures were explained in Inuktittut or English (as preferred), and consent forms were also completed in the language of the subject's choice.

To avoid the interobserver bias associated with incomplete sampling [12], subject recruitment was undertaken by the same observer, using the same methodology in each of the three surveys. Recruitment was about $50 \%$ of adults (table 1). The reported name, age and date of birth were checked against government and health centre records. With the consent of the subjects and the Baffin Regional Health Board, a simple history of respiratory and general health was checked against medical and radiographic records held at the Igloolik Health Centre. Because hunting is weather-dependent, subjects could not be tested to a rigid schedule; each of the three surveys continued in similar fashion from the early fall to the late spring of the following year, when all willing volunteers had been tested.

\section{Body build}

Height was measured to $0.5 \mathrm{~cm}$, and body mass to 0.1 $\mathrm{kg}$, using clinical scales calibrated against known standards.

\section{Pulmonary function}

Measurements were made in a centrally-heated laboratory; the ambient temperature was $20-22^{\circ} \mathrm{C}$, but the water content of the air was quite low. The same $13.5 l$ Stead-Wells spirometer, checked regularly for leaks, was used throughout. The one second forced expiratory volume in one second $\left(\mathrm{FEV}_{1}\right)$ and the forced vital capacity (FVC) were measured in conformity with International Biological Programme recommendations [13]. Subjects were allowed two practice attempts and three definitive trials at each visit, the reported value being the average of the three definitive readings. The average value is preferred relative to the maximum, particularly for longitudinal comparisons, since it yields a more stable value [13]. The maximal mid-expiratory flow rate (MMEF) was calculated from the same records, noting the time interval corresponding to expulsion of $25-75 \%$ of the FVC.

\section{Statistical analyses}

Subjects were grouped by age decade, and means and sDs were calculated. The method of least squares was used to fit cross-sectional gender specific multiple regression equations of the type:

$$
\mathrm{FVC}=\mathrm{a}(\mathrm{A})+\mathrm{b}(\mathrm{A})^{2}+\mathrm{c}(\mathrm{H})+\mathrm{d}(\mathrm{S})+\mathrm{e}
$$

where $\mathrm{A}$ is the age in years, $\mathrm{H}$ is the standing height in $\mathrm{cm}$, and $\mathrm{S}$ is the reported daily consumption of cigarettes. Lines were fitted both for all subjects, and "healthy subjects" with no history of respiratory disease. Longitudinal changes were calculated as a gender specific 10 year difference of lung volume for any given cohort (mean \pm SD). Multiple analysis of variance MANOVA was used to examine age decade, cohort, and age*cohort interactions for the three surveys.

\section{Results}

\section{Smoking habits}

Smoking commonly began early in puberty, and was widely prevalent among adults (table 2). There was a slight trend for cigarette withdrawal as adults of each cohort became older, but even in old age smoking was more prevalent than in Southern Canada. The reported daily cigarette consumption in the three surveys (males: $13 \pm 6,17 \pm 9,13 \pm 8$; females: $9 \pm 6,12 \pm 6,11 \pm 7$ ) was lower than in Southern Canada, with no consistent secular trend.

\section{Respiratory disease}

Many subjects gave a history of physician-diagnosed or radiographic respiratory disease (31\% in 1969/ $1970,56 \%$ in $1979 / 1980$, and $41 \%$ in $1989 / 1990)$; the diagnosis was usually a prior tuberculous infection, currently controlled.

Table 2. - A comparison of smoking prevalence from the three surveys classified by age decade (percentage of subjects in each age category)

\begin{tabular}{lccccccc}
\hline \multirow{2}{*}{$\begin{array}{l}\text { Age } \\
\text { yrs }\end{array}$} & \multicolumn{3}{c}{ Males } & & \multicolumn{3}{c}{ Females } \\
\cline { 2 - 3 } \cline { 6 - 8 } & & & & & & & \\
& $1969 / 70$ & $79 / 80$ & $89 / 90$ & & $1969 / 70$ & $79 / 80$ & $89 / 90$ \\
\hline $20-29$ & 97 & 95 & 93 & & 100 & 92 & 96 \\
$30-39$ & 83 & 71 & 79 & & 92 & 96 & 81 \\
$40-49$ & 88 & 78 & 63 & & 100 & 94 & 68 \\
$50-59$ & 86 & 80 & 80 & & 50 & 100 & 58 \\
\hline
\end{tabular}




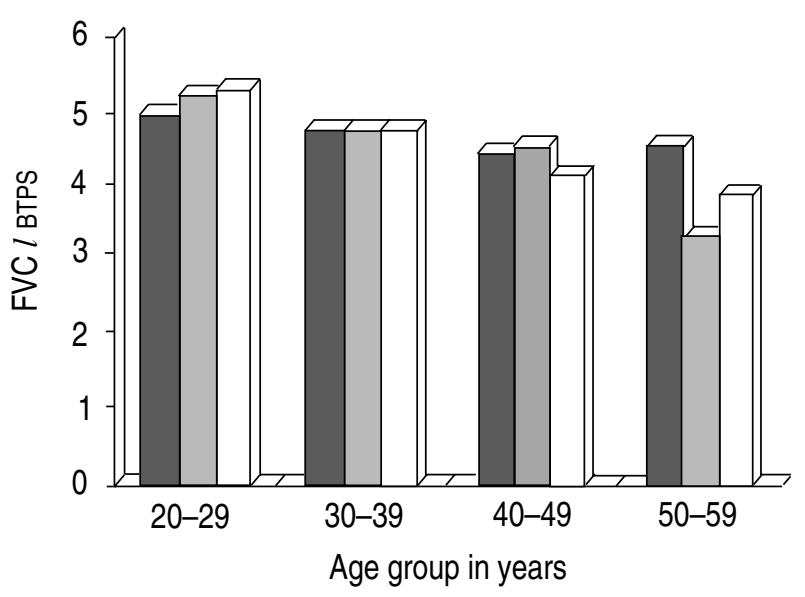

Fig. 1 - Forced vital capacity (FVC) of male Inuit as observed in; $\square: 1969 / 1970$; $\square$ : 1979/1980; and $\square$ : 1989/1990. BTPS: body temperature and pressure saturated with water vapour.

\section{Forced vital capacity}

Cross-sectional data showed a secular trend to an increase of FVC in the youngest age decade (figs 1 and 2 ), little change in those aged 30-39 or 40-49 yrs, and a large decrease in those aged 50-59 yrs (apparently between 1969/1970 and 1979/1980, although subject numbers in this age category were small). Multiple regression equations indicated no impact of smoking habits upon FVC, except for one marginal coefficient in female subjects $(1989 / 1990$ only; $\mathrm{p}<0.061)$. The age ${ }^{2}$ term also lacked statistical significance, except for a weak effect among females in 1989/1990 ( $\mathrm{p}<0.033)$. Accordingly, equations fitted simply for age (yrs) and standing height (cm) were used to compare FVC between the three surveys.

Age coefficients for the entire sample (table 3) increased from 1969/1970 to $1989 / 1990$ (males:16.5 versus $52.3 \mathrm{ml} \cdot \mathrm{yr}^{-1}$ females; 27.3 versus $36.5 \mathrm{ml} \cdot \mathrm{yr}^{-1}$ ). Data for females with no history of respiratory disease (26.5 $\mathrm{ml} \cdot \mathrm{yr}^{1}$ in $1969 / 1970,28.7 \mathrm{ml} \cdot \mathrm{yr}^{-1}$ in 1989/1990) suggested that much of the apparent secular trend could reflect ageing of a diseased cohort. However, healthy males showed an age coefficient of $15.7 \mathrm{ml} \cdot \mathrm{yr}^{-1}$ in $1969 / 1970$, rising to $43.6 \mathrm{ml} \cdot \mathrm{yr}^{-1}$ in $1989 / 1990$. In a typical $165 \mathrm{~cm}$

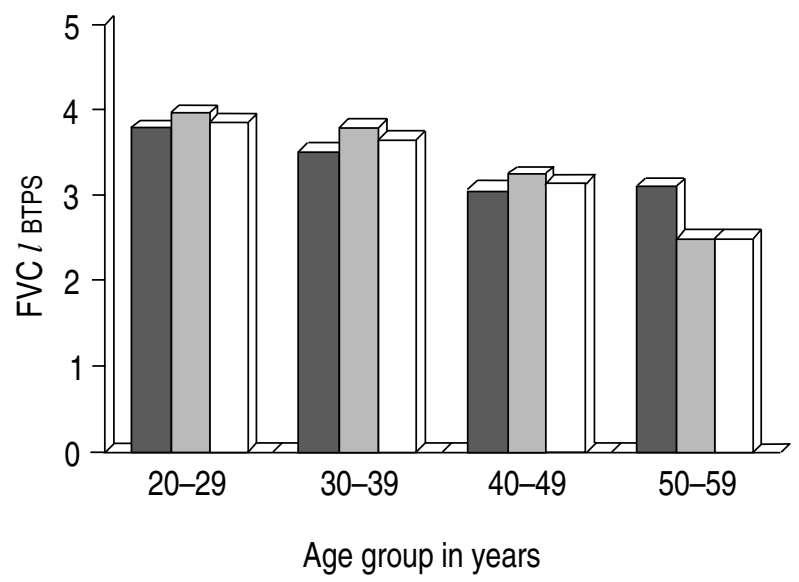

Fig. 2. - Forced vital capacity of female Inuit as observed in: $\square$ 1969/1970; $\square$ : 1979/1980; and $\square: 1989 / 1990$. BTPS: body temperature and pressure saturated with water vapour. male aged 20 yrs, the FVC predicted from our regression equation increased significantly from $5.09 l$ in $1969 / 1970$ to $5.48 l$ in $1979 / 1980$, and $5.62 l$ in $1989 / 1990$ (table 3). In contrast, the predicted FVC at an age of 60 yrs decreased significantly from $4.43 l$ in $1969 / 1970$ to $3.62 l$ in $1979 / 1980$, and $3.53 l$ in $1989 / 1990$ (table 3). Predictions for a $155 \mathrm{~cm}$ female showed a small increase at $20 \mathrm{yrs}$, from $3.92 l$ in $1969 / 1970$ to $4.26 l$ in $1979 / 1980$ and 4.14 in $1989 / 1990$, but predicted values at 60 yrs showed little change $(2.83 l$ in 1969/1970, $2.88 l$ in $1979 / 1980$ and $2.64 l$ in 1989/1990).

The longitudinal data suggested an acceleration of lung function loss as subjects became older (table 4), with little difference between decades commencing in $1969 / 1970$ and $1979 / 1980$. In those initially aged $20-30$ yrs, respective figures for the two cohorts were 17.1 and $6.0 \mathrm{ml} \cdot \mathrm{yr}^{-1}$ in the males, and 15.1 and $18.9 \mathrm{ml} \cdot \mathrm{yr}^{-1}$ in the females. In those initially aged 30-50 yrs, values were 73.6 and $45.7 \mathrm{ml} \cdot \mathrm{yr}^{-1}$ for the males, and 25.5 and 42.3 $\mathrm{ml} \cdot \mathrm{yr}^{-1}$ for the females. Cross-sectional estimates for the periods $1969 / 1970$ to $1979 / 1980$, and $1979 / 1980$ to $1989 / 1990$ were 24.0 and $37.9 \mathrm{ml} \cdot \mathrm{yr}^{-1}$ in the males, and 30.9 and $35.5 \mathrm{ml} \cdot \mathrm{yr}^{-1}$ in the females.

MANOVA showed significant effects of age-decade $(\mathrm{p}<0.001)$ and of age-decade*cohort $(\mathrm{p}<0.011)$ in the males, but only of age-decade $(\mathrm{p}<0.001)$ in the females.

\section{Forced expiratory volume in one second}

Cross-sectional data patterns were very similar to those for FVC (table 3). Smoking habits contributed little to the variance of $\mathrm{FEV}_{1}$, with the exception of a marginal effect $(p<0.052)$ in the females of $1989 / 1990$. $\mathrm{Age}^{2}$ terms were not statistically significant in 1969/1970 or $1979 / 1980$, but in $1989 / 1990$ quadratic terms increased $\mathrm{r}^{2}$ from 0.662 to 0.681 for the males $(\mathrm{p}<0.021)$, and from 0.766 to 0.786 for the females $(\mathrm{p}<0.010)$. Because this effect was small, cohort comparisons were again based on age and height alone.

Overall age coefficients increased from 1969/1970 to 1989/1990, (22.2 versus $51.1 \mathrm{ml} \cdot$ year $^{-1}$ in the men, 27.1 versus $37.9 \mathrm{ml} \cdot \mathrm{yr}^{-1}$ in the females, table 3$)$. In healthy subjects, the increase was smaller (18.5 versus 39.7 $\mathrm{ml} \cdot \mathrm{yr}^{-1}$ in the males, 26.9 versus $31.5 \mathrm{ml} \cdot \mathrm{yr}^{-1}$ in the females. Predicted values for a typical 20 year old man increased (4.04 $l$ in $1969 / 1970,4.55 l$ in $1979 / 1980,4.71 l$ in $1989 / 1990)$, but predictions decreased at $60 \mathrm{yrs}$ of age (3.16 $l$ in 1969/1970, $2.66 l$ in 1989/1990). In females, predicted values at age $20 \mathrm{yrs}$ increased $(3.16 l$ in $1969 / 1970,3.54 l$ in 1989/1990), but showed little change at $60 \mathrm{yrs}(2.07 l$ in 1969/1970, $2.02 l$ in 1989/1990).

Longitudinal estimates of ageing showed substantial curvilinearity, and (in the males) a trend for slower ageing from 1969/1970 to 1979/1980 than from 1979/1980 to $1989 / 1990$ (table 4). In males, respective values were 4.2 versus $22.3 \mathrm{ml} \cdot \mathrm{yr}^{-1}$ (initial age 20-30 yr) and 32.4 versus $54.2 \mathrm{ml} \cdot \mathrm{yr}^{-1}$ (pooled data for actual ages 30-40 and $40-50 \mathrm{yr}$ ). In the females, corresponding values were 13.1 versus $18.0 \mathrm{ml} \cdot \mathrm{yr}^{-1}$ and 28.8 versus $28.3 \mathrm{ml} \cdot \mathrm{yr}^{-1}$.

Overall cross-sectional estimates for the periods 1969/ 1970 to $1979 / 1980$ and $1979 / 1980$ to $1989 / 1990$ were 
Table 3. - Multiple regression equations of the type: $F V C$ or $\mathrm{FEV}_{1}=\mathrm{a}(\mathrm{age}, \mathrm{yrs})+\mathrm{b}$ (height, $\left.\mathrm{cm}\right)+\mathrm{c}$ for the prediction of vital capacity ( $l$, BTPS) and one second forced expiratory volume (FEV $)_{1}$ in Inuit aged 20-60 yrs, with calculated typical values for male of height $165 \mathrm{~cm}$ and female of height $155 \mathrm{~cm}$ at ages shown

\begin{tabular}{|c|c|c|c|c|c|c|}
\hline \multirow{2}{*}{$\begin{array}{c}\text { Subject grol } \\
\text { decade }\end{array}$} & \multirow[b]{2}{*}{$\mathrm{n}$} & \multicolumn{3}{|c|}{ Constants (mean \pm SEM) } & \multicolumn{2}{|c|}{ Typical volume $l$} \\
\hline & & $\mathrm{a} \times 100$ & $\mathrm{~b} \times 100$ & $\mathrm{c}$ & $20 \mathrm{yrs}$ & $60 \mathrm{yrs}$ \\
\hline \multicolumn{7}{|c|}{ Forced vital capacity (FVC) } \\
\hline \multicolumn{7}{|l|}{ All men } \\
\hline 1969/70 & 69 & $-1.65 \pm 0.71$ & $+5.19 \pm 1.21$ & $-4.32 \pm 2.06$ & 5.09 & 4.43 \\
\hline $79 / 80$ & 97 & $-4.63 \pm 0.64$ & $+7.50 \pm 1.29$ & $-5.97 \pm 2.18$ & 5.48 & 3.62 \\
\hline $89 / 90$ & 119 & $-5.23 \pm 0.53$ & $+5.58 \pm 1.04$ & $-2.54 \pm 1.74$ & 5.62 & 3.53 \\
\hline \multicolumn{7}{|c|}{ Healthy men } \\
\hline $69 / 70$ & 49 & $-1.57 \pm 0.82$ & $+5.33 \pm 1.28$ & $-3.34 \pm 2.21$ & 5.15 & 4.52 \\
\hline $79 / 80$ & 50 & $-3.22 \pm 0.79$ & $+5.72 \pm 1.54$ & $-3.37 \pm 2.51$ & 5.35 & 4.14 \\
\hline $89 / 90$ & 70 & $-4.36 \pm 0.91$ & $+4.20 \pm 1.24$ & $-0.34 \pm 2.07$ & 5.56 & 3.82 \\
\hline \multicolumn{7}{|c|}{ All women } \\
\hline $69 / 70$ & 49 & $-2.73 \pm 0.69$ & $+0.57 \pm 0.29$ & $+3.57 \pm 0.48$ & 3.92 & 2.83 \\
\hline $79 / 80$ & 70 & $-3.45 \pm 0.57$ & $+6.34 \pm 1.07$ & $-4.88 \pm 1.70$ & 4.26 & 2.88 \\
\hline $89 / 90$ & 92 & $-3.65 \pm 0.38$ & $+5.23 \pm 0.81$ & $-3.23 \pm 1.27$ & 4.14 & 2.64 \\
\hline \multicolumn{7}{|c|}{ Healthy women } \\
\hline $69 / 70$ & 32 & $-2.65 \pm 0.90$ & $+3.45 \pm 1.30$ & $-0.88 \pm 2.07$ & 3.94 & 2.88 \\
\hline $79 / 80$ & 24 & $-3.15 \pm 0.80$ & $+8.61 \pm 1.61$ & $-8.41 \pm 2.55$ & 4.30 & 3.04 \\
\hline $89 / 80$ & 55 & $-2.87 \pm 0.46$ & $+6.18 \pm 0.87$ & $-4.87 \pm 1.35$ & 4.14 & 2.99 \\
\hline \multicolumn{7}{|c|}{ Forced expiratory volume in one second $\left(\mathrm{FEV}_{1}\right)$} \\
\hline \multicolumn{7}{|c|}{ All men } \\
\hline $69 / 70$ & 69 & $-2.22 \pm 0.74$ & $+3.69 \pm 1.27$ & $-1.61 \pm 2.16$ & 4.04 & 3.16 \\
\hline $79 / 80$ & 97 & $-5.30 \pm 0.60$ & $+5.63 \pm 1.20$ & $-3.69 \pm 2.03$ & 4.55 & 2.43 \\
\hline $89 / 90$ & 119 & $-5.11 \pm 0.49$ & $+4.62 \pm 0.95$ & $-1.90 \pm 1.60$ & 4.71 & 2.66 \\
\hline \multicolumn{7}{|c|}{ Healthy men } \\
\hline $69 / 70$ & 49 & $-1.85 \pm 0.85$ & $+3.01 \pm 1.34$ & $-0.56 \pm 2.31$ & 4.02 & 2.87 \\
\hline $79 / 80$ & 50 & $-3.65 \pm 0.63$ & $+5.15 \pm 1.22$ & $-3.31 \pm 2.00$ & 4.46 & 3.00 \\
\hline $89 / 90$ & 74 & $-3.97 \pm 0.82$ & $+3.27 \pm 1.12$ & $-0.53 \pm 1.88$ & 4.66 & 3.07 \\
\hline \multicolumn{7}{|c|}{ All women } \\
\hline $69 / 70$ & 49 & $-2.71 \pm 0.65$ & $+7.90 \pm 2.75$ & $+2.48 \pm 0.46$ & 3.16 & 2.07 \\
\hline $79 / 80$ & 70 & $-3.62 \pm 0.52$ & $+5.25 \pm 0.97$ & $-3.90 \pm 1.54$ & 3.52 & 2.07 \\
\hline $89 / 90$ & 92 & $-3.79 \pm 0.42$ & $+4.26 \pm 0.88$ & $-2.31 \pm 1.38$ & 3.54 & 2.02 \\
\hline \multicolumn{7}{|c|}{ Healthy women } \\
\hline $69 / 70$ & 32 & $-2.69 \pm 0.91$ & $+2.17 \pm 1.33$ & $+0.36 \pm 2.11$ & 3.19 & 2.11 \\
\hline $79 / 80$ & 24 & $-3.42 \pm 0.79$ & $+7.92 \pm 1.59$ & $-8.02 \pm 2.51$ & 3.57 & 2.20 \\
\hline $89 / 90$ & 54 & $-3.15 \pm 0.48$ & $+5.56 \pm 0.92$ & $-4.43 \pm 1.43$ & 3.55 & 2.30 \\
\hline
\end{tabular}

BTPS: body temperature and pressure saturated with water vapour.

37.6 and $52.1 \mathrm{ml} \cdot \mathrm{yr}^{-1}$ in the males, and 31.8 and 37.2 $\mathrm{ml} \cdot \mathrm{yr}^{-1}$ in the females.

MANOVA showed significant effects of age-decade $(\mathrm{p}<0.001)$ and age-decade*cohort $(\mathrm{p}<0.005)$ in the males, but in the females only the age-decade term was significant $(\mathrm{p}<0.001)$.

\section{Maximal mid-expiratory flow rate}

Smoking habits did not contribute to the variance of MMEF, and age ${ }^{2}$ terms were significant only in 1989/1990. Respective values of $\mathrm{r}^{2}$ for the linear and the quadratic equations were 0.550 and 0.600 in the males, and 0.605

Table 4. - Ageing of forced vital capacity and forced expiratory volume in one second $\left(l\right.$ (BTPS) $\left.\cdot \mathrm{yr}^{-1} \times 100\right)$, as estimated from longitudinal data

\begin{tabular}{lcccc}
\hline $\begin{array}{l}\text { Initial age } \\
\text { yrs }\end{array}$ & \multicolumn{2}{c}{ Males } & \multicolumn{2}{c}{ Females } \\
\cline { 2 - 5 } Forced vital capacity & $1970-1980$ & $1980-1990$ & $1970-1980$ & $1980-1990$ \\
$20-30$ & $1.71 \pm 4.56$ & $0.60 \pm 2.52$ & $1.51 \pm 1.82$ & $1.89 \pm 1.25^{* * *}$ \\
$30-40$ & $6.13 \pm 3.58^{* * *}$ & $4.49 \pm 3.55^{* * *}$ & $1.85 \pm 2.44$ & $4.32 \pm 1.55^{* * *}$ \\
$40-50$ & $8.58 \pm 3.40^{* *}$ & $4.64 \pm 1.93^{* * *}$ & $3.25 \pm 2.04$ & \\
Forced expiratory volume in one second & & & $1.14 \pm 3.10^{* * *}$ \\
$20-30$ & $0.42 \pm 2.14$ & $2.23 \pm 3.46^{*}$ & $1.31 \pm 1.45^{*}$ & $3.35 \pm 2.75$ \\
$30-40$ & $2.63 \pm 3.28^{* *}$ & $4.87 \pm 2.53^{* * *}$ & $2.73 \pm 2.43^{* *}$ & $2.30 \pm 1.36^{*}$ \\
$40-50$ & $3.85 \pm 1.55^{* * *}$ & $5.96 \pm 1.94^{* *}$ & $3.03 \pm 2.21^{* *}$ & \\
\hline
\end{tabular}

Significance of difference between 1970-80 and 1980-90 cohorts *: p<0.05; **: p<0.01; ***: p<0.001. BTPS: body temperature and pressure saturated with water vapour. 
Table 5. - Equations of the type: $\operatorname{MMEF}\left(l \cdot \mathrm{s}^{-1}\right)=\mathrm{a}(\mathrm{age}, \mathrm{yrs})+\mathrm{b}$ (height, $\left.\mathrm{cm}\right)+\mathrm{c}$ for the prediction of maximal midexpiratory flow rate $\left(l \cdot \mathrm{s}^{-1}\right.$, BTPS) of Inuit aged 20-60 yrs, with typical values for male of $165 \mathrm{~cm}$ and female of $155 \mathrm{~cm}$ height

\begin{tabular}{|c|c|c|c|c|c|c|}
\hline \multirow{2}{*}{$\begin{array}{l}\text { Subject group } \\
\text { decade }\end{array}$} & \multirow[b]{2}{*}{$\mathrm{n}$} & \multicolumn{3}{|c|}{ Constants (mean $\pm \mathrm{SE})$} & \multicolumn{2}{|c|}{ Typical Values $l \cdot \mathrm{s}^{-1}$} \\
\hline & & $\mathrm{a} \times 100$ & $\mathrm{~b} \times 100$ & $\mathrm{c}$ & $20 \mathrm{yrs}$ & $60 \mathrm{yrs}$ \\
\hline \multicolumn{7}{|l|}{ All men } \\
\hline $79 / 80$ & 97 & $-7.72 \pm 1.06$ & $+5.01 \pm 2.14$ & $-1.89 \pm 3.61$ & 4.82 & 1.75 \\
\hline $89 / 90$ & 119 & $-6.26 \pm 1.07$ & $+5.13 \pm 2.08$ & $-2.10 \pm 3.49$ & 5.11 & 3.28 \\
\hline \multicolumn{7}{|l|}{ Healthy men } \\
\hline $79 / 80$ & 50 & $-5.95 \pm 1.40$ & $+6.96 \pm 2.74$ & $-5.51 \pm 4.47$ & 4.78 & 2.41 \\
\hline $89 / 90$ & 70 & $-3.71 \pm 1.79$ & $+2.07 \pm 2.43$ & $+2.38 \pm 4.06$ & 5.06 & 3.57 \\
\hline \multicolumn{7}{|l|}{ All women } \\
\hline $79 / 80$ & 70 & $-5.82 \pm 1.12$ & $+4.92 \pm 2.08$ & $-2.54 \pm 3.30$ & 3.93 & 1.60 \\
\hline $89 / 90$ & 92 & $-5.51 \pm 0.87$ & $+3.36 \pm 1.86$ & $-0.15 \pm 2.90$ & 4.11 & 1.90 \\
\hline \multicolumn{7}{|c|}{ Healthy women } \\
\hline $79 / 80$ & 24 & $-4.78 \pm 2.02$ & $+11.67 \pm 4.07$ & $-13.17 \pm 6.44$ & 3.96 & 2.05 \\
\hline $89 / 90$ & 54 & $-5.04 \pm 1.11$ & $+6.49 \pm 2.10$ & $-4.84 \pm 3.25$ & 4.21 & 2.20 \\
\hline
\end{tabular}

MMEF: maximal mid-expiratory flow rate; BTPS: body temerature and pressure saturated with water vapour.

Table 6. - Change of maximal mid-expiratory flow rate $\left(l \cdot \mathrm{s}^{-1} \times 100\right.$ per year), as estimated from longitudinal data (1980-1990)

\begin{tabular}{ccc}
\hline $\begin{array}{c}\text { Initial age } \\
\text { yrs }\end{array}$ & Males & Females \\
\hline $20-30$ & $+1.62 \pm 4.16$ & $-0.75 \pm 5.12$ \\
$30-40$ & $+0.39 \pm 7.11$ & $-0.24 \pm 5.56$ \\
$40-50$ & $-5.92 \pm 6.08^{*}$ & $-2.43 \pm 2.91^{*}$ \\
\hline
\end{tabular}

*: $\mathrm{p}<0.05$.

and 0.653 in the females. To allow comparison with $\mathrm{FVC}$ and $\mathrm{FEV}_{1}$, cross-sectional analyses were based on age and height alone (table 5).

Overall data for 1979/1980 showed age constants of 77 and $58 \mathrm{ml} \cdot \mathrm{s}^{-1}$ per yr in the males and females respectively; corresponding slopes for healthy subjects were 60 and $48 \mathrm{ml} \cdot \mathrm{s}^{-1}$ per yr. In 1989/1990, overall values improved to 63 and $37 \mathrm{ml} \cdot \mathrm{s}^{-1}$ per $\mathrm{yr}$ in males and females, respectively. Longitudinal data (table 6) showed less change, except in men initially aged 40-50 yrs.

MANOVA showed significant effects of age-decade $(\mathrm{p}<0.001$ in both sexes), and cohort $(\mathrm{p}<0.007$ in males, $\mathrm{p}<0.025$ in women).

\section{Discussion}

\section{Data interpretation}

Whereas cross-sectional data suggested a secular trend to a roughly equal decrease of both $\mathrm{FVC}$ and $\mathrm{FEV}_{1}$ affecting both males and females, the longitudinal data suggested that the main change was a decrease of $\mathrm{FEV}_{1}$ in the males.

Artifacts can distort both cross-sectional comparisons of successive cohorts and longitudinal data [14], particularly when the community is small. If successive surveys have differing objectives (for example, disease detection versus fitness assessment), average results can be substantially distorted by small differences in popu- lation sampling $[12,15]$. We were able to recruit about $50 \%$ of adults, less than optimal, but a larger and better defined sample than in many previous surveys of indigenous peoples. Linkage to a fitness survey probably biased sampling, but in a consistent manner, since the same observer recruited and tested subjects throughout. The cross-sectional estimates of ageing match those reported in other surveys of indigenous populations [12], although higher age coefficients may have been observed if we had tested a partial sample with a medical bias.

Selective migration has biased some cross-sectional analyses [16]. We were fortunate that in 1969/1970, the last Inuit of the Igloolik region had just moved into permanent settlement housing, and there was as yet little outward migration. Nevertheless, continuing hunters were sometimes absent for substantial periods, limiting our ability to test all subjects in all three surveys.

Curvilinearity of the ageing process [17-19] could influence results in an aging population. It is possible to allow for curvilinearity by use of a statistical breakpoint [18] or a quadratic equation [14]. Our cross-sectional data showed few significant quadratic terms. Nevertheless, curvilinearity could have been masked by limitations of sample size, a suggestion supported by the longitudinal data. We thus controlled for the potential influence of an increasing number of elderly survivors by restricting the age range to 20-60 yrs.

Test learning can affect longitudinal comparisons, but the learning of simple spirometry is only a minor factor, even with a 3 year rather than a 10 year intertest interval [14]. Since the same observer used the same equipment throughout, differences in motivation and test mechanics were also avoided. Difficulty in controlling the precise date of individual observations was accepted as an unavoidable constraint in this population.

\section{Data analysis}

Given the general absence of significant coefficients relating to smoking habits and age $^{2}$, regression equations 
included only age and height terms. Many currently available surveys have reported data in this form. An alternative tactic (the use of lung volume ratios [14] was judged inappropriate, because substantial changes of stature were occurring even in young adults [9]. Changing stature also precluded one tactic for combining crosssectional and longitudinal information [14]. Accordingly, longitudinal trends were grouped by age-decade, and age-decade and cohort effects were analyzed jointly by MANOVA.

In urban populations, longitudinal estimates of lung function ageing have been both greater [14], and smaller $[1,4,20]$ than cross-sectional values, depending on the relative strengths of the various factors biasing the two estimates. In the present study, the longitudinal data suggested a curvilinearity of ageing. Relative to cross-sectional averages, the longitudinal losses of FVC and $\mathrm{FEV}_{1}$ were, thus, smaller for young adults, and greater for older individuals.

The FVC of a typical 20 year old male increased by $0.4-0.5 l$ from $1969 / 1970$ to $1989 / 1990$; this presumably reflects an improvement of health during childhood. In contrast, the FVC of a 60 year old man decreased by 0.6-0.7 $l$, with parallel trends in $\mathrm{FEV}_{1}$. The secular trend to a faster ageing of male $\mathrm{FEV}_{1}$ was confirmed in longitudinal data, and cannot, thus, be dismissed as an artifact of altered population demographics or curvilinearity of the ageing process. Potential explanations are discussed below.

\section{Cigarette smoking}

Cigarette smoking commonly increases the ageing of lung function [21-23], although the effect becomes statistically insignificant if allowance is made for an associated history of chronic chest disease [18]. The smoking history of the Inuit is unfortunately imprecise. Possibly, the oldest cohorts have had less pack-years of exposure; this could explain why the overall crosssectional slope in $1969 / 1970$ was shallower than that for many urban communities, and could also contribute to a more rapid ageing of respiratory function in latercohorts.

\section{Chronic respiratory disease}

Many Inuit still have radiographically diagnosed disease, but a comparison of regression equations including and excluding such individuals suggest that such disease currently has only a minor influence on age coefficients. Attention should be directed rather towards the possible impact of nonspecific viral infections, which are now endemic from early childhood.

\section{Cold air}

The secular trend to a faster ageing of lung function in the males cannot be explained by changes in the test environment; ambient conditions were similar for males and females, and did not change from one survey to the next. However, acculturation could have changed the cold exposure of male villagers. SCHAEFER et al. [24] argued that exposure to arctic air caused an accelerated ageing of lung function and pulmonary hypertension. Cross-sectional age coefficients for Arctic Bay [24] exceeded those for Igloolik, but we have also seen an above-average prevalence of right branch bundle block [25]. The reduction of hunting activity has undoubtedly decreased the duration of cold air exposure for the Inuit, but the intensity of exposure could have increased, since operation of high-speed snowmobiles displaces the "cushion" of warm air that previous generations inspired from within the hoods of their parkas.

\section{Snowmobile trauma}

Regular operation of high-speed snowmobiles over rough snow and ice has been associated with a $2-3 \mathrm{~cm}$ decrease of stature in male Inuit over the past two decades [9], apparently attributable to a longitudinal compression of the thoracic spine. However, this would have affected regression coefficients only to the extent that standing height became unrepresentative of thoracic dimensions; a $1 \%$ error in predicting thoracic length would give a volume discrepancy of $<3 \%$, insufficient to account for all of the observed acceleration of ageing. Compression of the thoracic spine could also impede thoracic mechanics, although the change of stature seems rather small to have any major impact.

\section{Indoor air pollution}

Traditional Inuit families were exposed to high concentrations of soot from whale oil lamps [24]. The Igloolik population had electric lighting and electric or oil furnace heating over the period of this study. The homes are small and firmly sealed against the arctic cold, and since most of the family are smokers, there is now exposure to environmental cigarette smoke from an early age. However, any impact upon adult respiratory function [26] is likely to have been overshadowed by the effects of personal cigarette smoking from an early age.

\section{Loss of physical fitness}

Over the $20 \mathrm{yrs}$ of observation, there have been large decreases in aerobic power and muscle strength, with an increase of body fat [8]. These changes, also, could contribute to the loss of lung function [12].

\section{Conclusion}

Cross-sectional and longitudinal data agree in showing a secular trend to accelerated ageing of $\mathrm{FEV}_{1}$ in Igloolik men. The most likely explanations seem to be a greater inspiration of cold air during snowmobile operation, alterations of chest mechanics associated with spinal compression, and a deterioration of physical fitness; all three of these items have affected males more than females over the 20 yrs of observation. 


\section{References}

1. Glindmeyer HW, Diem JE, Jones RN, et al.Noncomparability of longitudinally and cross-sectionally determined annual change in spirometry. Am Rev Resp Dis 1982; 125: 544-548.

2. Johnson BD, Dempsey JA. Demand versus capacity in the ageing pulmonary system. Ex Sport Sci Rev 1991; 19: $171-210$.

3. Shephard RJ. Aging, lung function and exercise. J Phys Activ Ageing 1993; 1: 59-83.

4. Vollmer WM, Johnson LR, McCamant LE, Buist AS. Longitudinal versus cross-sectional estimation of lung function decline: further insights. Stats in Med 1988; 7: 685-696.

5. Rode A, Shephard RJ. Pulmonary function of Canadian Eskimos. Scand J Respir Dis 1973; 54: 191-205.

6. Godin G, Shephard RJ, Activity patterns of the Canadian Eskimo. In: Edholm O, Gunderson EK ed. Polar Human Biology. London, Heinemann, 1973.

7. Rode A, Shephard RJ. Cardiorespiratory fitness of an Arctic community. J Appl Physiol 1971; 31: 519-526.

8. Rode A, Shephard RJ. In: Fitness and Health of an Inuit Community: 20 Years of Cultural Change. Ottawa, Circumpolar and Scientific Affairs, 1992.

9. Shephard RJ, Goodman J, Rode A, Schaefer O. Snowmobile use and decrease of stature among the Inuit. Arct Med Res 1984; 38: 32-36.

10. Rode A, Shephard RJ. Ten years of "civilization": fitness of Canadian Inuit. J Appl Physiol: Respiriat Environ Exercise Physiol 1984; 56: 1472-1477.

11. Rode A, Shephard RJ. Lung function in a cold environment: a current perspective. In: R. Fortuine, ed. Circumpolar Health 1984. Seattle, University of Washington, 1985; pp. 60-63.

12. Shephard RJ. In Human Physiological Work Capacity. London, Cambridge University Press, 1978.

13. Weiner JS, Lourie JA. In: Practical Human Biology. London, Academic Press, 1981.

14. Ware JH, Dockery DW, Louis TA, Xu X, Ferris BG, Speizer FE. Longitudinal and cross-sectional estimates of pulmonary function decline in never-smoking adults. Am J Epidemiol 1990; 132: 685-700.
15. Shephard RJ. Work physiology and activity patterns. In: Milan FA. ed. The Human Biology of Circumpolar Populations. London, Cambridge University Press, 1980; pp. 305-338.

16. Miall WE, Ashcroft MT, Lovell HG, Moore F.A Longitudinal study of the decline of adult height in two Welsh communities. Hum Biol 1967; 39: 445454.

17. Shephard RJ. The physiological sequelae of segmental resection and other forms of thoracic treatment in flying personnel. RAF Institute Of Aviation Medicine, Farnborough, Hants. Report FPRC 1007, 1956; pp. 1-91.

18. Anderson TW, Brown JR, Hall JW, Shephard RJ. The limitations of linear regressions for the prediction of vital capacity and forced expiratory volume. Respiration 1968; 25: 140-158.

19. Dockery DW, Ware JH, Ferris BG. Distribution of forced expiratory volume in one second and forced vital capacity in healthy white adult never-smokers in six US cities. Am Rev Respir Dis 1985; 131:511-520.

20. Dockery DW, Ware JH, Ferris BG, et al. Longitudinal changes in forced expiratory volume in one second in adults: methodological considerations and findings in healthy nonsmokers. Am Rev Resp Dis 1986; 133: 974-980.

21. Bossé R, Sparrow D, Garvey AJ, et al Cigarette smoking, aging and decline in pulmonary function: A longitudinal study. Arch Environ Health 1980; 35: 247-252.

22. Ferris BG, Chen H, Puleo S, Murphy RLH. Chronic nonspecific respiratory disease in Berlin, New Hampshire, January 1966 to June 1967. Am Rev Resp Dis 1976; 113: 475-485.

23. Fletcher C, Peto R, Tinker C, Speizer FE.In: The Natural History of Chronic Bronchitis and Emphysema. Oxford: Oxford University Press, 1976.

24. Schaefer O, Eaton RDP, Timmermans FJW, Hildes JA. Respiratory function impairment and cardiopulmonary consequences in long-time residents of the Canadian Arctic. Can Med Assoc J 1980; 123: 997-1004.

25. Shephard RJ, Rode A. Right-branch bundle block in circumpolar Inuit. Arct Med Res 1991; 50: 120-126.

26. Shephard RJ. Respiratory irritation from environmental tobacco smoke. Arch Environ Health 1992; 47: 123-130. 